\title{
P3HT:PCBM/nickel-aluminum layered double hydroxide-graphene foam composites for supercapacitor electrodes
}

Damilola Momodu, Abdulhakeem Bello, Julien Dangbegnon, Farshad Barzeger, Mopeli Fabiane and Ncholu Manyala*

Department of Physics, Institute of Applied Materials, SARChI Chair in Carbon Technology and Materials, University of Pretoria, Pretoria 0028, South Africa.

*Corresponding author. E-mail address: ncholu.manyala@up.ac.za, Tel.: +27 012420 3549; Fax: +27 012420 2516 (N. Manyala)

\begin{abstract}
In this paper, a simple dip-coating technique is used to deposit a P3HT:PCBM/Nickel Aluminum layered double hydroxide-graphene foam (NiAl-LDH-GF) composite onto a nickel foam (NF) serving as a current collector. A self-organization of the polymer chains is assumed on the Ni-foam grid network during the slow "dark" drying process in normal air. Electrochemical cyclic voltammetry (CV) and constant charge-discharge (CD) measurements show an improvement in the supercapacitive behavior of the pristine P3HT:PCBM by an order of magnitude from $0.29 \mathrm{~F} \mathrm{~cm}^{-2}$ (P3HT:PCBM nanostructures) to $1.22 \mathrm{~F} \mathrm{~cm}^{-2}$ (P3HT:PCBM/NiAl-LDH-GF composite structure) resulting from the addition of NiAl-LDH-GF material at a current density of $2 \mathrm{~mA} \mathrm{~cm}^{-2}$. This capacitance retention after cycling at $10 \mathrm{~mA}$ $\mathrm{cm}^{-2}$ also demonstrates the electrode material's potential for supercapacitor applications.
\end{abstract}

Keywords: Dip coating, Р3HT:PCBM; Graphene foam; Nickel-aluminum layered double hydroxide (NiAl-LDH); supercapacitor 


\section{Introduction}

The rising energy demand for the future generation is one of the major concerns of most countries around the world today. The increasing cost of energy and the issues related to environmental pollution which are associated with energy production and use compel the search for alternative sources of energy that are renewable, sustainable, clean and efficient. This has stimulated intense research into new methods for energy generation and efficient storage. In order to provide a sustainable and continuous supply of energy to meet the everincreasing demand, there is a need to set up storage systems that will store excess energy produced by different energy-generation methods.

Supercapacitors (SCs, or ultracapacitors) and hybrid solid-state batteries are but a few examples of the most recent technological innovations in the field of electrical energy storage [1-9]. Among the latter, SCs possess higher power density and longer cycle life, but lower energy density. Therefore, one of the main aims in the ongoing research into SCs is to improve their energy densities considerably, to bring the densities close to those of batteries or even better [2]. For efficient energy storage, the performance of SCs should easily meet technological requirements in present and future applications. Some important factors that determine the performance of SCs include the nature of the electrode and the operating voltage. The storage mechanism is used to classify SCs into two main types: the electric double-layer capacitors (EDLCS), in which the charge is stored at the electrode/electrolyte interface with the main material used being carbon; and the pseudocapacitors in which the charge arises from reversible redox reactions in materials like conducting polymers, metal oxides or hydroxides, etc. [2, 4]. The electrode porous structure 
and material surface area are very important for optimum capacitance due to the surface phenomena associated with supercapacitors [4].

Graphene, planar sheet of $\mathrm{sp}^{2}$ bonded carbon atoms densely packed in a honeycomb lattice, has recently attracted much attention from scientific communities due to its unique properties such as high electrical conductivity, high surface area and robust mechanical properties $[4,10,11]$. In the past few years, many studies have focused on combining graphene with metal oxides or hydroxides [9, 12-16], conducting polymers [12, 17-19], and other activated carbon materials $[20,21]$. Among the conducting polymers, polyaniline (PANI) and poly (3-hexylthiophene) (P3HT), which have the characteristic property of donating electrons, have recently been used in SC applications $[17,18]$. Recent studies by A. Gupta et al.[17] involved an in situ synthesis of P3HT incorporated with graphene to form polymer/graphene composites with a good specific capacitance of $244 \mathrm{~F} \mathrm{~g}^{-1}$ at a current density of $0.2 \mathrm{~A} \mathrm{~g}^{-1}$. Other researchers have also blended the P3HT polymer with fullerene acceptor material: $[6,6]$-phenyl $\mathrm{C}_{61}$-butyric acid methylester (PCBM), to form a hybrid blend of highly ordered P3HT:PCBM nanostructures with efficient donor-acceptor charge carriers. Wang et al. [22] reported a capacitance value of $0.14 \mathrm{~F} \mathrm{~cm}^{-2}$ for nanowires of blend, obtained from cyclic voltammeBht:|(RCBMmeasurements. In general, conductive polymer blends with efficient electrical properties are obtained by an interpenetrating matrix of donor and acceptor materials. P3HT:PCBM blends have been extensively applied in organic solar cells [23-25] and recently in SCs due to their promising capacitive properties. However, reported values are still low due to the limited accessibility of electrolyte ions to the surface of the material $[22,26]$. This could be mitigated by hybridizing this polymer with 
a material with a high surface area and which has additional properties necessary to improve the overall capacitive performance of the final composite.

Layered double hydroxides (LDH), also known as hydrotalcite-like compounds, are a family of layered solids with structurally positively charged layers and interlayer balancing anions [27]. They have been used extensively for various applications due to their tunable composition, large surface area and flexible ion exchangeability [28, 29]. Hence the synergetic properties of both P3HT:PCBM and the LDHs should, in theory, improve the capacitive properties of the composite.

On the basis of the attractive properties of both graphene and LDH stated above, we report on the effect of the addition of nickel aluminum-LDH-graphene foam composite (NiAl-LDHGF) to the P3HT:PCBM polymer blend through a simple dip-coating approach in an effort to improve the capacitive performance of the latter. To the best of our knowledge, there has been no previous report on a composite of $\mathrm{LDH}$-graphene (LDH-G) with a P3HT:PCBM polymer blend for supercapacitor application.

\section{Experimental}

\section{Synthesis of NiAl-LDH-GF composite}

GF was synthesized by chemical vapor deposition (CVD) onto catalytic nickel foam (NF) (Alantum Innovations in Alloy Foam Munich, Germany). The nickel foam with graphene was then immersed in $3.0 \mathrm{M}$ hydrochloric acid $(\mathrm{HCl})$ at $80{ }^{\circ} \mathrm{C}$ for 8 hours to etch away the nickel template completely and thereafter rinsed several times in deionized water to obtain the graphene foam. NiAl-LDH composites were synthesized by adopting a facile solvothermal method reported in earlier work [3]. Typically, $2.400 \mathrm{~g}$ of urea, $2.139 \mathrm{~g}$ of $\mathrm{Ni}\left(\mathrm{NO}_{3}\right)_{2}$ and 
$0.724 \mathrm{~g}$ of $\mathrm{Al}\left(\mathrm{NO}_{3}\right)_{3}$ salts were dissolved in $80 \mathrm{ml}$ of a pre-sonicated deionized water/ethanol solution containing graphene foam. After ultrasonication for a few minutes, the above mixture was transferred into an autoclave vessel and kept at $140^{\circ} \mathrm{C}$ for 18 hours. Finally, the composite was filtered and dried at $60^{\circ} \mathrm{C}$ overnight for 8 hours to obtain the final material.

\section{Synthesis of P3HT-PCBM blend}

Regioregular P3HT and PCBM (Sigma-Aldrich, purity $>99.9 \%$ ) were used as received without further purification. In the preparation of the polymer blend, $45 \mathrm{mg}$ of $\mathrm{P} 3 \mathrm{HT}$ and $40 \mathrm{mg}$ of PCBM (with a ratio of $\mathrm{P} 3 \mathrm{HT}: \mathrm{PCBM}=1: 0.8$ ) were dissolved in $3 \mathrm{ml}$ of 1,2-chlorobenzene to form a $15 \mathrm{mg} / \mathrm{ml}$ solution.

\section{Synthesis of P3HT-PCBM/NiAI-LDH-GF composite}

Ninety milligrams of the NiAl-LDH-GF powder obtained was dissolved and sonicated in $1 \mathrm{ml}$ of ethanol. The solutions of P3HT:PCBM and NiAl-LDH-GF were then mixed and sonicated for 2 hours. Lastly, the mixed solution was stirred for 24 hours in the dark at $65{ }^{\circ} \mathrm{C}$ in order to obtain thorough mixing of the final product of the P3HT:PCBM/NiAl-LDH-GF composite. Thereafter, the composite solution was applied via a simple dip-coating technique to preweighed nickel foam $\left(3 \times 1 \mathrm{~cm}^{2}\right)$ as illustrated in Fig. 1. The foam was then re-weighed to obtain the amount of material coated onto it and the coated area was also measured. This was then placed in a dark enclosure and allowed to dry slowly in normal air overnight due to the instability of the polymer blend under normal light [30]. Nickel foam dip coated with a solution containing $\mathrm{P} 3 \mathrm{HT}: \mathrm{PCBM}$ blend alone was also prepared simultaneously for comparison purposes. The morphology of the samples was studied with a high-resolution Zeiss Ultra Plus 55 field emission scanning electron microscope (FE-SEM) operated at $1.0 \mathrm{kV}$. 
Raman spectra of the P3HT:PCBM, GF, NiAl-LDH and P3HT:PCBM/Ni-Al-LDH-GF composite were recorded using a Jobin-Yvon Horiba TX 6400 micro-Raman spectrometer equipped with a triple monochromator system to eliminate contributions from Rayleigh scattering. The samples were analyzed with a $514 \mathrm{~nm}$ argon excitation laser using a 509 objective lens with $100 x$ magnification and an acquisition time of $120 \mathrm{~s}$. Surface area measurements were performed using the Brunauer-Emmett-Teller (BET) method. Pore size and pore volume were obtained using Barrett-Joyner-Halenda (BJH) method from the desorption branch of the isotherm. Electrochemical measurements were carried out using a Bio-Logic SP300 workstation (Knoxville TN 37930, USA) in a three electrode configuration. The as-prepared P3HT:PCBM/NiAl-LDH-GF on NF served as the working electrode, a glassy carbon plate was used as the counter electrode and $\mathrm{Ag} / \mathrm{AgCl}(3.0 \mathrm{M} \mathrm{KCl}$ solution) was used as the reference electrode in a $6.0 \mathrm{M} \mathrm{KOH}$ electrolyte. Electrochemical impedance spectroscopy (EIS) was performed in the frequency range of $100 \mathrm{kHz}-10 \mathrm{mHz}$.

\section{Results and discussion}

Figure 2 shows the morphology of the NF before and after coating with the P3HT:PCBM/NiAl-LDH-GF composite. Fig. 2a shows the three-dimensional (3D) NF macroporous structure which makes it an excellent choice for use as a current collector. The inset to Fig. $2 a$ is of higher magnification showing the grain boundaries of the NF. Fig. $2 b$ shows the NF coated with the P3HT:PCBM polymer blend. A view at a higher magnification is shown in the inset to Figure $2 \mathrm{~b}$ with dark patches appearing on the NF after coating. Figure $2 \mathrm{c}$ shows the NF coated with the P3HT:PCBM/NiAl-LDH-GF composite material. The presence of the composite material is evidenced at higher magnification of $1 \mu \mathrm{m}$ by the rough ridges appearing on the NF after dip coating in the composite solution (see inset to 
Fig. 2c). As reported in an earlier study [22], a random orientation of the polymer chains occurs during a fast drying process. However, a slow drying process enhances a thermodynamically favorable re-orientation of the polymer chains leading to ordered nanostructures of the polymer on the supporting substrate. Thus, a degree of polymer nanostructure ordering should also occur on the supporting $\mathrm{Ni}$ foam; however, one should bear in mind that the addition of NiAl-LDH and graphene to the polymer solution may be detrimental for this ordering during dip coating.

Raman spectroscopy was used here to confirm the presence of the constituents of the composite material by studying their characteristic vibrational modes. Figure 3 shows the Raman spectra for NiAl-LDH, the P3HT:PCBM blend and the P3HT:PCBM/NiAl-LDH-GF composite. The inset to the figure shows the Raman spectrum of GF. The peaks seen in the spectrum correspond to those of the composite material and are typical of each component of the composite with the bands at $1594 \mathrm{~cm}^{-1}$ and $2704 \mathrm{~cm}^{-1}$ corresponding to the $\mathrm{G}$ and $2 \mathrm{D}$ bands of graphene, but shifted because of the interaction between graphene and other materials in the composite (see the inset to Fig. 3) [31-33]. The peak at $\sim 1365 \mathrm{~cm}^{-1}$ and the shoulder appearing at $\sim 1445 \mathrm{~cm}^{-1}$ are very close to those related to the vibrational modes from the $\mathrm{C}-\mathrm{C}$ intra-ring and the symmetric $\mathrm{C}=\mathrm{C}$ stretching modes in the $\mathrm{P} 3 \mathrm{HT}: \mathrm{PCBM}$ blend respectively [34-36]. These two modes, usually described as 'in-plane ring skeleton modes', are used to quantify the degree of molecular order of the P3HT phase in the blend due to the fact that they are sensitive to $\pi$-electron delocalization of P3HT molecules [34]. The vibrational mode for fullerene-derived PCBM films usually appears at $1469 \mathrm{~cm}^{-1}$, based on earlier literature, and can be assigned to the dominant pentagonal-pinch mode $A_{g}(2)$ of $C_{60}$ [37]. The Raman peak at around $1469 \mathrm{~cm}^{-1}$ is usually overshadowed by the intense peak at 
$\sim 1450 \mathrm{~cm}^{-1}$ and cannot be resolved in our spectrum [36]. The band at $\sim 1025 \mathrm{~cm}^{-1}$ is typical of the NiAl-LDH vibrational mode [4, 33]. Furthermore, the Raman spectrum for the P3HT:PCBM/NiAl-LDH-GF composite clearly shows a broadening of the peaks at 1365 and $\sim 1445 \mathrm{~cm}^{-1}$. This is accompanied by a reduction in the intensity of those peaks. These observations could be explained by the coexistence of the different materials of the composite which disrupts the initial order of the P3HT:PCBM polymer matrix [34]. Thus, from the Raman spectra one can suggest that there is an interaction between the GF, the LDH material and the P3HT:PCBM blend.

The supercapacitive performance of the P3HT:PCBM/NiAl-LDH-GF composite electrode material is dependent on its ability to accommodate as much active electrochemical sites for charge storage during operation. The presence of suitable mesopores within the electrode material (especially within the range of $2-5 \mathrm{~nm}$ ) are also ideal to ensure the reduction of mass transfer of electrolyte during fast redox reactions [4]. As such, surface area measurements using BET technique is necessary. The physical adsorption/desorption of $\mathrm{N}_{2}$ at $77 \mathrm{~K}$ results shown in Figure 4 displays the surface area and porosity for the prepared samples.

In the case of LDH alone, a type IV isotherm with a $\mathrm{H}_{3}$-type hysteresis loop $\left(\mathrm{P} / \mathrm{P}_{\mathrm{o}}>0.4\right)$ appears which indicates the presence of mesopores in the LDH material $[4,38]$ with an estimated specific surface area (SSA) of $57.8249 \mathrm{~m}^{2} \mathrm{~g}^{-1}$. A higher BET SSA of $68.09 \mathrm{~m}^{2} \mathrm{~g}^{-1}$ was observed for the NiAl-LDH-GF where GF has been added thereby increasing the availability of porous sites suitable for the polymer composite and possibly reducing the aggregation of LDH platelets (Fig. 4b). Thus, the addition of the mesoporous material to the P3HT:PCBM polymer blend was done to increase the surface area of the polymer based composite, improving its charge storage capability by the availability of active mesoporous sites. This 
improvement is shown in Fig. 4c where the SSA of the P3HT:PCBM/NiAI-LDH-GF composite is drastically increased to $22.33 \mathrm{~m}^{2} \mathrm{~g}^{-1}$ from an initial value of $2.58 \mathrm{~m}^{2} \mathrm{~g}^{-1}$ for the P3HT:PCBM blend alone. Fig. 4d shows the pore size distribution for the composite with a pore diameter range of $2-5 \mathrm{~nm}$ which shows the successful inclusion of mesoporous sites necessary for charge storage.

Figure 5a compares the CV curves of the NF current collector, the pristine P3HT:PCBM blend and the P3HT:PCBM/NiAl-LDH-GF composite at a scan rate of $10 \mathrm{mV} \mathrm{s}^{-1}$. The CV curve of the NF current collector shows a very low current density response when compared to P3HT:PCBM and the P3HT:PCBM/NiAl-LDH-GF composite respectively. This shows the negligible capacitive contribution of the NF current collector in both the P3HT:PCBM and the P3HT:PCBM/NiAl-LDH-GF composite active electrodes. The CV measurements at different scan rates of the pristine $\mathrm{P} 3 \mathrm{HT}$ :PCBM are shown in Fig. 5b. The oxidation and reduction peaks appear at 0.35 and $0.24 \mathrm{~V}$ respectively. The ratio of the absolute values of the anodic to cathodic current $\left(I_{p a} / I_{p c}\right)$ is approximately unity, which is a clear indication that the redox reaction of $\mathrm{P} 3 \mathrm{HT}: \mathrm{PCBM}$ is a reversible process. The CV curves of the P3HT:PCBM/NiAl-LDHGF composite shown in Fig. 5c, also at different scan rates, exhibit higher current responses when compared to the pristine $\mathrm{P} 3 \mathrm{HT}: \mathrm{PCBM}$, indicating a better capacitive performance. The specific capacitance was calculated using the following formula from the CV curves [17]:

$C\left(\frac{}{2}\right) \quad \overline{\bar{a} v(V \quad 1)} \int_{V}^{V_{2}} I(V)$ 
where $\bar{a}$ is the area of the coated surface with the active material (in $\mathrm{cm}^{2}$ ), $v$ is the scan rate (in $\mathrm{mV} / \mathrm{s}$ ), $V_{1}$ and $V_{2}$ are the integration limits and $I(V)$ is the response current during the $\mathrm{CV}$ measurement.

A higher specific capacitance was obtained for the composite which contains the LDH-GF material, for each scan rate. For example, a specific capacitance of the pristine P3HT:PCBM nanostructure on NF is calculated as $0.34 \mathrm{~F} \mathrm{~cm}^{-2}$, while an improved value of $0.92 \mathrm{~F} \mathrm{~cm}^{-2}$ is recorded for the P3HT:PCBM/NiAl-LDH-GF composites, both at $10 \mathrm{mV} \mathrm{s}^{-1}$. Fig. $5 \mathrm{~d}$ shows the trend of the specific capacitance as a function of the scan rate. As expected, the specific capacitance decreases with increasing scan rate. This is due to the limited movement of ions and protons by diffusion at higher scan rates, which leaves only the outer active surface for charge storage $[4,39]$.

Figures $6 \mathrm{a}$ and $6 \mathrm{~b}$ show the variation in discharge time with current density for both pristine P3HT:PCBM and the P3HT:PCBM/NiAI-LDH-GF composite respectively. A higher discharge time is observed for the composite material compared to the P3HT:PCBM polymer. The presence of the graphene and hydrotalcite structure within the polymer creates more surface interaction for charge transport. The mechanism of the charge storage for the polymer alone is based on both interfacial electric double-layer capacitance (EDLC) and redox processes from pseudocapacitance. The EDLC is based on electrostatic charge separation and accumulation while the redox process arises from the electron transfer between the $\mathrm{P}_{3} \mathrm{HT}^{+}$donor and $\mathrm{PCBM}^{-}$acceptor with electrosorption and surface redox processes at the electrolyte/electrode material interface. Similar pseudocapacitive nature has been reported for other conductive polymers which have been used for supercapacitor applications [17][18]. For an ideal SC, the discharge curves should be linear; however, the 
non-linearity observed in the composite material confirms the pseudocapacitive nature of the LDH material and the polymer blend.

The specific capacitance was also calculated from the galvanostatic CD curves using the formula [28]:

$$
(\mathrm{F} \quad) \quad \overline{\bar{a} \Delta}
$$

where $I$ is a current $(A), T_{d}$ is the discharge time (s), $\bar{a}$ is the area of the coated electrode with active material (in $\mathrm{cm}^{2}$ ), and $\Delta V$ is the voltage range (in $\mathrm{V}$ ).

An improvement in specific capacitance was also observed from the charge-discharge measurements for the composite containing the LDH-GF material. For example, at a current density of $2 \mathrm{~mA} \mathrm{~cm}^{-2}$, the specific capacitance was found to increase from $0.29 \mathrm{~F} \mathrm{~cm}^{-2}$ for the pristine $\mathrm{P} 3 \mathrm{HT}: \mathrm{PCBM}$ nanostructure to a value of $1.22 \mathrm{~F} \mathrm{~cm}^{-2}$ for the composite structure. Thus the results of both the CV and CD measurements showed improved capacitance of the polymer due to the presence of the NiAl-LDH-GF. The improvement is attributed to the creation of active mesopores necessary for charge storage in the composite material. This is seen from the improvement in the specific surface area obtained from the BET analysis.

Fig. $6 \mathrm{c}$ shows the continuous CD curve of the composite at a current density of $10 \mathrm{~mA} \mathrm{~cm}$. The composite retained $75 \%$ of its initial capacitance after 500 galvanostatic CD cycles, which shows reliable stability of the composite material for use as an SC electrode. Most polymer electrodes begin to exhibit degradation after 200 - 300 cycles due to mechanical degradation during cycling [40], hence the idea of adding other materials to form a composite which will improve the overall polymer stability. Furthermore, in an effort to 
study the effect of cycling on the electrochemical stability of the P3HT:PCBM/NiAl-LDH-GF composite, the electrodes were subjected to CV tests once again after 500 cycles. An insignificant shift was observed in the redox peaks after cycling as illustrated in Fig. $6 \mathrm{~d}$. This further confirms the stability of the composite electrode for possible applications in supercapacitors.

The electrochemical impedance spectroscopy (EIS) result for the composite electrode is shown in Fig. 6e (Nyquist plot), alongside that of the P3HT:PCBM. The Nyquist plot is a representation of the real and imaginary parts of the impedance in the electrode material. The plot is usually divided into two regions, namely the high-frequency region, which is characteristic of the charge-transfer process taking place at the electrode/electrolyte interface, and a straight line in the low-frequency region, which represents the diffusion process taking place at this interface. The intercept in the high-frequency region with the $\mathrm{x}$-axis corresponds to the equivalent series resistance (ESR), which consists of the resistance of the aqueous electrolyte and the intrinsic resistance of the composite material [4]. An internal resistance of $0.2 \Omega$ was recorded for the composite electrode,(figure inset) which is very similar to that of the $\mathrm{P} 3 \mathrm{HT}$ :PCBM polymer. This suggests that there was no change in the internal resistance resulting from the addition of the LDH-GF material. 


\section{Conclusion}

We synthesized and incorporated NiAl-LDH-GF into a P3HT:PCBM polymer to obtain a composite material with an improved specific capacitive behavior. The composite exhibits a specific capacitance of $1.22 \mathrm{~F} \mathrm{~cm}^{-2}$ at a current density of $2.0 \mathrm{~mA} \mathrm{~cm}$ from galvanostatic charge-discharge measurements, and $0.92 \mathrm{~F} \mathrm{~cm}^{-2}$ at a scan rate of $10 \mathrm{mV} \mathrm{s}^{-1}$ from cyclic voltammetry measurements, which is an order of magnitude higher than for the pristine sample and is, to the best of our knowledge, among the highest values reported so far for P3HT:PCBM nanostructure supercapacitors [22]. The 75\% capacitance retention of the composite after 500 galvanostatic charge-discharge cycles also shows the reliable stability of the composite material for use in energy storage devices. 


\section{Acknowledgments}

This work is based on research supported by the South African Research Chairs Initiative (SARChI) of the Department of Science and Technology (DST) and the National Research Foundation (NRF).

Any opinion, findings and conclusions or recommendations expressed in this work are those of the authors and therefore the NRF and DST do not accept any liability with regard thereto. D.M acknowledges the financial support from University of Pretoria PhD bursary scheme for his study. 


\section{References}

1. Conway B (1991) Transition from "supercapacitor" to "battery" behavior in electrochemical energy storage. J Electrochem Soc 138:1539-1548.

2. Tao Y, Ruiyi L, Zaijun L, Junkang L, Guangli W, Zhiquo G (2013) A free template strategy for the fabrication of nickel/cobalt double hydroxide microspheres with tunable nanostructure and morphology for high performance supercapacitors. RSC Adv 3:19416.

3. Song Y, Wang J, Li Z, Guan D, Mann T, Liu Q, Zhang M, Liu L (2012) Self-assembled hierarchical porous layered double hydroxides by solvothermal method and their application for capacitors. Microporous Mesoporous Mater 148:159-165.

4. Yang W, Gao Z, Wang J, Ma, J, Zhang, M, Liu, L (2013) Solvothermal one-step synthesis of $\mathrm{Ni}-\mathrm{Al}$ layered double hydroxide/carbon nanotube/reduced graphene oxide sheet ternary nanocomposite with ultrahigh capacitance for supercapacitors. ACS Appl Mater Interfaces 5:5443-5454.

5. Simon P, Gogotsi Y (2008) Materials for electrochemical capacitors. Nat Mater 7:845-854.

6. Notten PHL, Roozeboom F, Niessen RAH, Baggetto L (2007) 3D Integrated All Solid State Rechargeable Batteries. Adv Mater 19:4564-4567.

7. Ruzmetov D, Oleshko VP, Haney PM, Lezec, HJ, Karki K, Baloch KH, Agrawal AK, Davydov AV, Krylyuk S, Liu Y (2011) Electrolyte stability determines scaling limits for solid-state 3D Li ion batteries. Nano Lett 12:505-511.

8. Hall PJ, Mirzaeian M, Fletcher SI, Sillars FB, Rennie AJR, Shitta-Bey GO, Wilson G, Cruden A, Carter R (2010) Energy storage in electrochemical capacitors: designing functional materials to improve performance. Energy Environ Sci 3:1238-1251.

9. Tao Y, Haiyan Z, Ruiyi L, Zaijun L, Junkang L, Guangli W, Zhiquo G (2013) Microwave synthesis of nickel/cobalt double hydroxide ultrathin flowerclusters with threedimensional structures for high-performance supercapacitors. Electrochim Acta 111:71-79.

10. Yang W, Ratinac KR, Ringer SP, Thordarson P, Gooding JJ, Braet F (2010) Carbon nanomaterials in biosensors: should you use nanotubes or graphene? Angew Chemie Int Ed 49:2114-2138.

11. Neto AHC, Castro Neto AH, Peres NMR, Neto AHC, Castro NAH, Peres NMR, Novoselov KS, Geim AK (2009) The electronic properties of graphene. Rev Mod Phys 81:109-162.

12. Shen J, Yang C, Li X, Wang G (2013) High-performance asymmetric supercapacitor based on nanoarchitectured polyaniline/graphene/carbon nanotube and activated graphene electrodes. ACS Appl Mater Interfaces 5:8467-76. 
13. Bello A, Fashedemi OO, Fabiane M, Lekitima JN, Ozoemena KI, Manyala N (2013) Microwave assisted synthesis of $\mathrm{MnO} 2$ on nickel foam-graphene for electrochemical capacitor. Electrochim Acta 114:48-53.

14. Bello A, Makgopa K, Fabiane M, Dodoo-Ahrin D, Ozoemena KI, Manyala N (2013) Chemical adsorption of $\mathrm{NiO}$ nanostructures on nickel foam-graphene for supercapacitor applications. J Mater Sci 40:6707-6712.

15. Khamlich S, Bello A, Fabiane M, Ngom BD, Manyala N (2013) Hydrothermal synthesis of simonkolleite microplatelets on nickel foam-graphene for electrochemical supercapacitors. J Solid State Electrochem 17:2879-2886.

16. Bello A, Fashedemi OO, Lekitima JN, Fabiane Mopeli, Dodoo-Arhin D, Ozoemena KI, Gogotsi Y, Charlie Johnson AT, Manyala N (2013) High-performance symmetric electrochemical capacitor based on graphene foam and nanostructured manganese oxide. AIP Adv 3:082118.

17. Gupta A, Akhtar AJ, Saha SK (2013) In-situ growth of P3HT/graphene composites for supercapacitor application. Mater Chem Phys 140:616-621.

18. Wu Q, Xu Y, Yao Z, Liu A, Shi G (2010) Supercapacitors Based on Flexible Graphene/Polyaniline Nanofiber Composite Films. ACS Nano 4:1963-1970.

19. Lai L, Yang H, Wang L, Teh BK, Zhong J, Chou H, Chen L, Chen W, Shen Z, Ruoff RS, Lin J (2012) Preparation of supercapacitor electrodes through selection of graphene surface functionalities. ACS Nano 6:5941-51.

20. Stoller M, Park S, Zhu Y, An J, Ruoff, RS (2008) Graphene-based ultracapacitors. Nano Lett 8:3498-502.

21. Zhang W, Ma C, Fang J, Cheng J, Zhang X, Dong S, Zhang L (2013) Asymmetric electrochemical capacitors with high energy and power density based on graphene/CoAI-LDH and activated carbon electrodes. RSC Adv 3:2483-2490.

22. Wang YZ, Wang Q, Xie HY, Xie HY, Ho LP, Tan DMF, Diao YY, Chen W, Xie XN (2012) Fabrication of highly ordered P3HT:PCBM nanostructures and its application as a supercapacitive electrode. Nanoscale 4:3725-3728.

23. Dennler G, Scharber MC, Brabec CJ (2009) Polymer-Fullerene Bulk-Heterojunction Solar Cells. Adv Mater 21:1323-1338.

24. Gomez De Arco L, Zhang Y, Schlenker CW, Ryu K, Thompson ME, Zhou C (2010) Continuous, highly flexible, and transparent graphene films by chemical vapor deposition for organic photovoltaics. ACS Nano 4:2865-2873.

25. Tan, M. J., Zhong, S., Li, J., Chen, Z., \& Chen W (2013) Air-Stable Efficient Inverted Polymer Solar Cells Using Solution-Processed Nanocrystalline ZnO Interfacial Layer. ACS Appl Mater Interfaces 5:4696-4701. 
26. Zhang Z, Chen X, Chen P, Guan G, Qiu L, Lin H, Yang Z, Bai W, Luo Y, Peng H (2014) Integrated Polymer Solar Cell and Electrochemical Supercapacitor in a Flexible and Stable Fiber Format. Adv Mater 26:466-470.

27. Wang J, Zhou J, Li Z, Liu Q, Yang P, Jing X, Zhang M (2010) Design of magnetic and fluorescent $\mathrm{Mg}-\mathrm{Al}$ layered double hydroxides by introducing Fe3O4 nanoparticles and Eu3+ ions for intercalation of glycine. Mater Res Bull 45:640-645.

28. Wang J, Song Y, Li Z, Liu, Q, Zhou J, Jing X, Zhang M, Jiang Z (2010) In Situ Ni/Al Layered Double Hydroxide and Its Electrochemical Capacitance Performance. Energy \& Fuels 24:6463-6467.

29. Wang Q, O'Hare D (2012) Recent advances in the synthesis and application of layered double hydroxide (LDH) nanosheets. Chem Rev 112:4124-4155.

30. Rivaton A, Chambon S, Manceau M (2010) Light-induced degradation of the active layer of polymer-based solar cells. Polym Degrad Stab 95:278-284.

31. Ferrari A, Basko D (2013) Raman spectroscopy as a versatile tool for studying the properties of graphene. Nat Nanotechnol 8:235-46.

32. Ferrari AC, Robertson J (2000) Interpretation of Raman spectra of disordered and amorphous carbon. Phys Rev B 61:14095.

33. Gao Z, Wang J, Li Z, Yang W, Wang B (2011) Graphene nanosheet/Ni2+/Al3+ layered double-hydroxide composite as a novel electrode for a supercapacitor. Chem Mater 23:3509-3516.

34. Tsoi WC, James DT, Kim JS, Nicholson PG, Murphy CE, Bradley DDC, Nelson J, Kim JS (2011) The nature of in-plane skeleton Raman modes of P3HT and their correlation to the degree of molecular order in P3HT:PCBM blend thin films. J Am Chem Soc 133:9834-43.

35. Saini V, Li Z, Bourdo S, Dervishi E, Xu Y, Ma X, Kunets, VP, Salamo GJ, Viswanathan T, Biris, AR, Saini D, Biris AS (2009) Electrical, Optical, and Morphological Properties of P3HT-MWNT Nanocomposites Prepared by in Situ Polymerization. J Phys Chem C 113:8023-8029.

36. Falke S, Eravuchira P, Materny A, Lienau C (2011) Raman spectroscopic identification of fullerene inclusions in polymer/fullerene blends. J Raman Spectrosc 42:1897-1900.

37. Kuzmany H, Matus M, Burger B, Winter J (1994) Raman Scattering in C60 fullerenes and fullerides. Adv Mater 6:731-745.

38. Yu J, Yu JC, Ho W, Leung MKP, Cheng B, Zhang G, Zhao X, (2003) Effects of alcohol content and calcination temperature on the textural properties of bimodally mesoporous titania. Appl Catal A Gen 255:309-320. 
39. Lao ZJ, Konstantinov K, Tournaire Y, Ng SH, Wang GX, Liu HK (2006) Synthesis of vanadium pentoxide powders with enhanced surface-area for electrochemical capacitors. J Power Sources 162:1451-1454.

40. Wang G, Zhang L, Zhang J (2012) A review of electrode materials for electrochemical supercapacitors. Chem Soc Rev 41:797-828. 


\section{Figure captions}

Fig. 1 Illustration of dip-coating technique using P3HT:PCBM/NiAl-LDH-GF solution

Fig. 2 SEM image of: (a) Ni-foam (NF); (b) P3HT:PCBM on NF; (c) P3HT:PCBM/NiAl-LDH-GF on NF (Insets in (a), (b), (c) show a higher magnification view at $1 \mu \mathrm{m}$ of the region in the square on the NF)

Fig. 3 Raman spectra of NiAl-LDH (green spectrum), GF (blue spectrum in figure inset), P3HT:PCBM (red spectrum) and P3HT:PCBM/NiAI-LDH-GF (black spectrum) respectively; (Note: Diamond symbol denotes LDH peak, star symbol denotes P3HT:PCBM peaks and flower symbol denotes graphene peaks)

Fig. 4 (a-c) $\mathrm{N}_{2}$ adsorption/desorption isotherms for NiAI-LDH, NiAl-LDH-GF, P3HT:PCBM and P3HT:PCBM/NiAl-LDH-GF samples (b) the pore size distribution of the P3HT:PCBM/NiAlLDH-GF composite

Fig. 5 Cyclic voltammetry curves of: (a) NF, P3HT:PCBM and P3HT:PCBM/NiAl-LDH-GF samples at $10 \mathrm{mV} \mathrm{s}^{-1}$ scan rate in a $6 \mathrm{M} \mathrm{KOH}$ three electrode configuration; (b) and (c) P3HT:PCBM alone and P3HT:PCBM/NiAl-LDH-GF composite respectively measured at scan rates of $5-40 \mathrm{mV} \mathrm{s}^{-1}$; (d) specific capacitance of P3HT:PCBM/NiAl-LDH-GF composite electrode at different scan rates calculated from the CV curves

Fig. 6 Galvanostatic charge-discharge profiles of: (a) P3HT:PCBM/NiAl-LDH-GF and (b) P3HT:PCBM electrodes at different current densities in a three electrode configuration; (c) the capacity retention of the composite at a current density of $10 \mathrm{~mA} \mathrm{~cm}{ }^{-2}$ (the inset to the 
figure shows the continuous charge-discharge curve); (d) the CV curves of P3HT:PCBM/NiAlLDH-GF on NF at $10 \mathrm{mV} \mathrm{s}^{-1}$ scan rate before and after cycling showing stability of the electrode and (e) the Nyquist plot for the pristine P3HT:PCBM polymer alone and P3HT:PCBM/NiAl-LDH-GF composite electrode. 


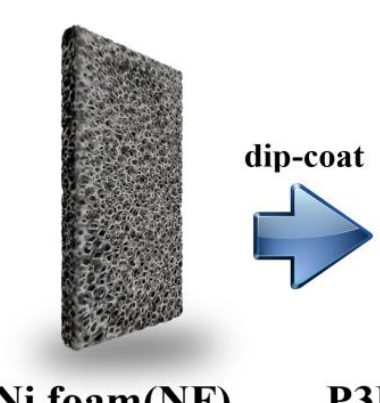

Ni foam(NF)

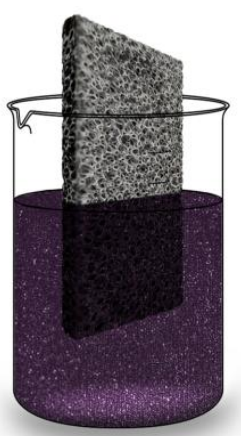

slow drying

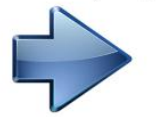

P3HT:PCBM/NiAl LDH-G coated on NF

Fig. 1 


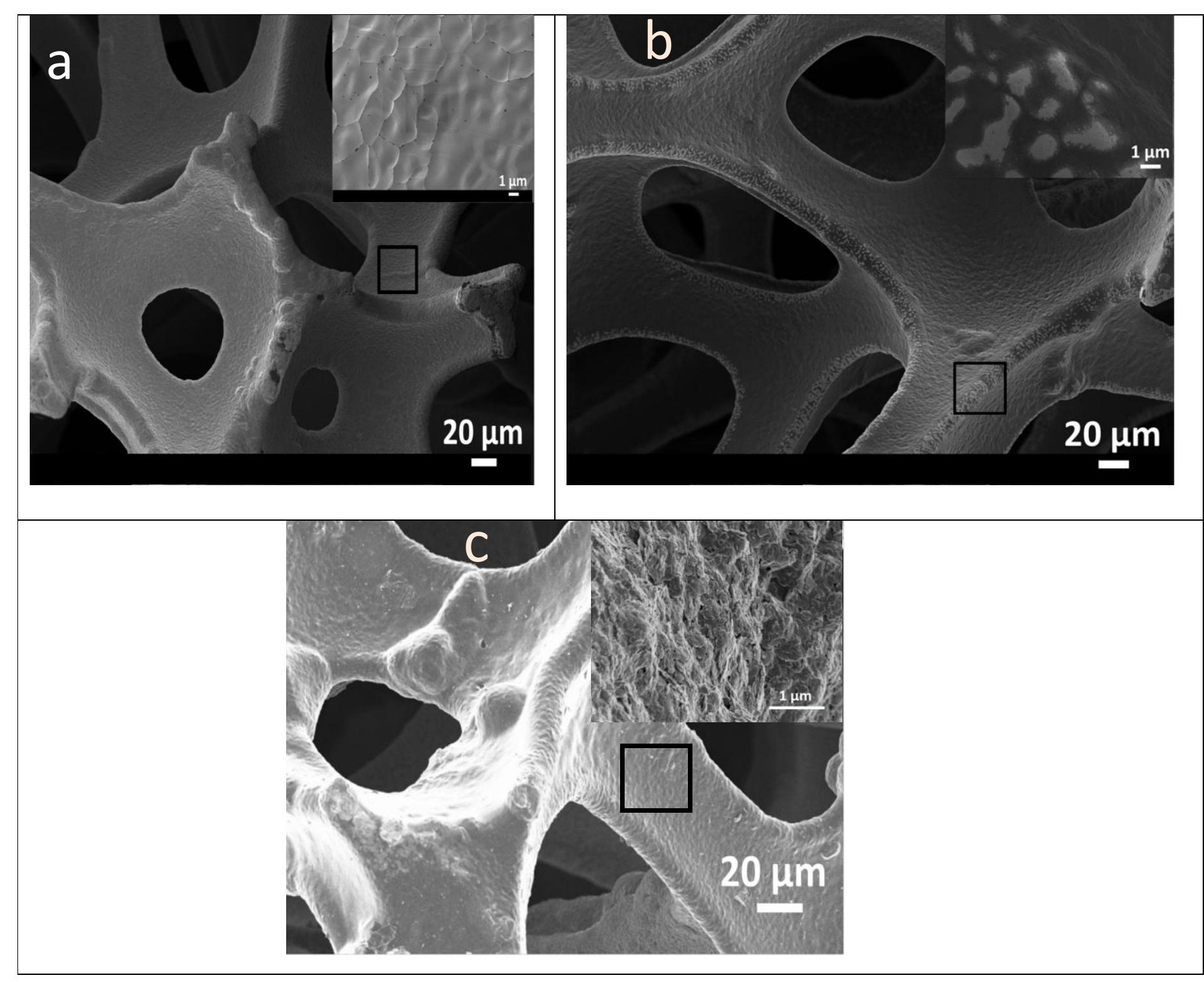

Fig. 2 


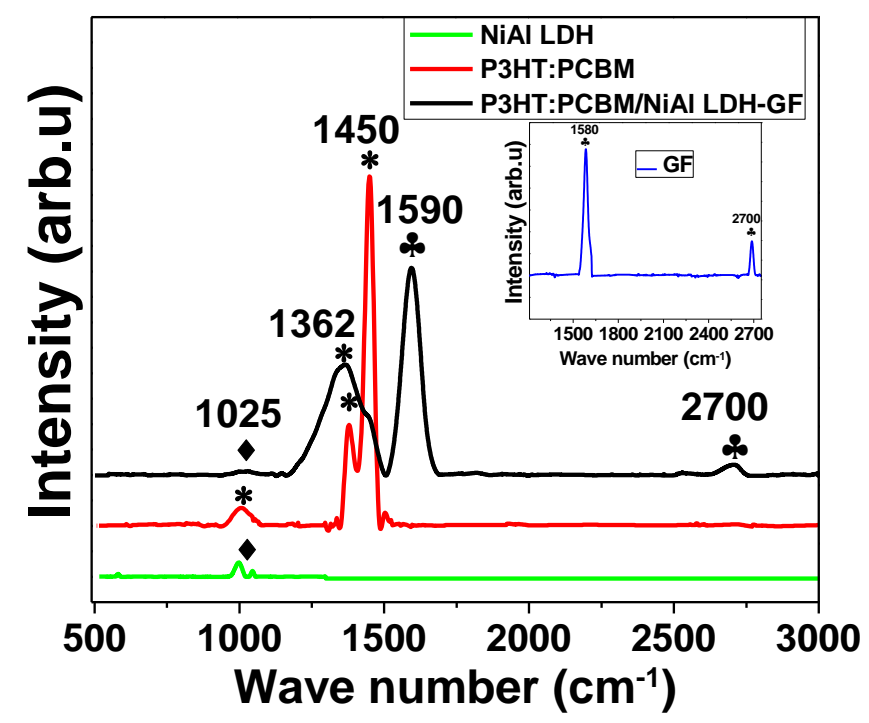

Fig. 3 

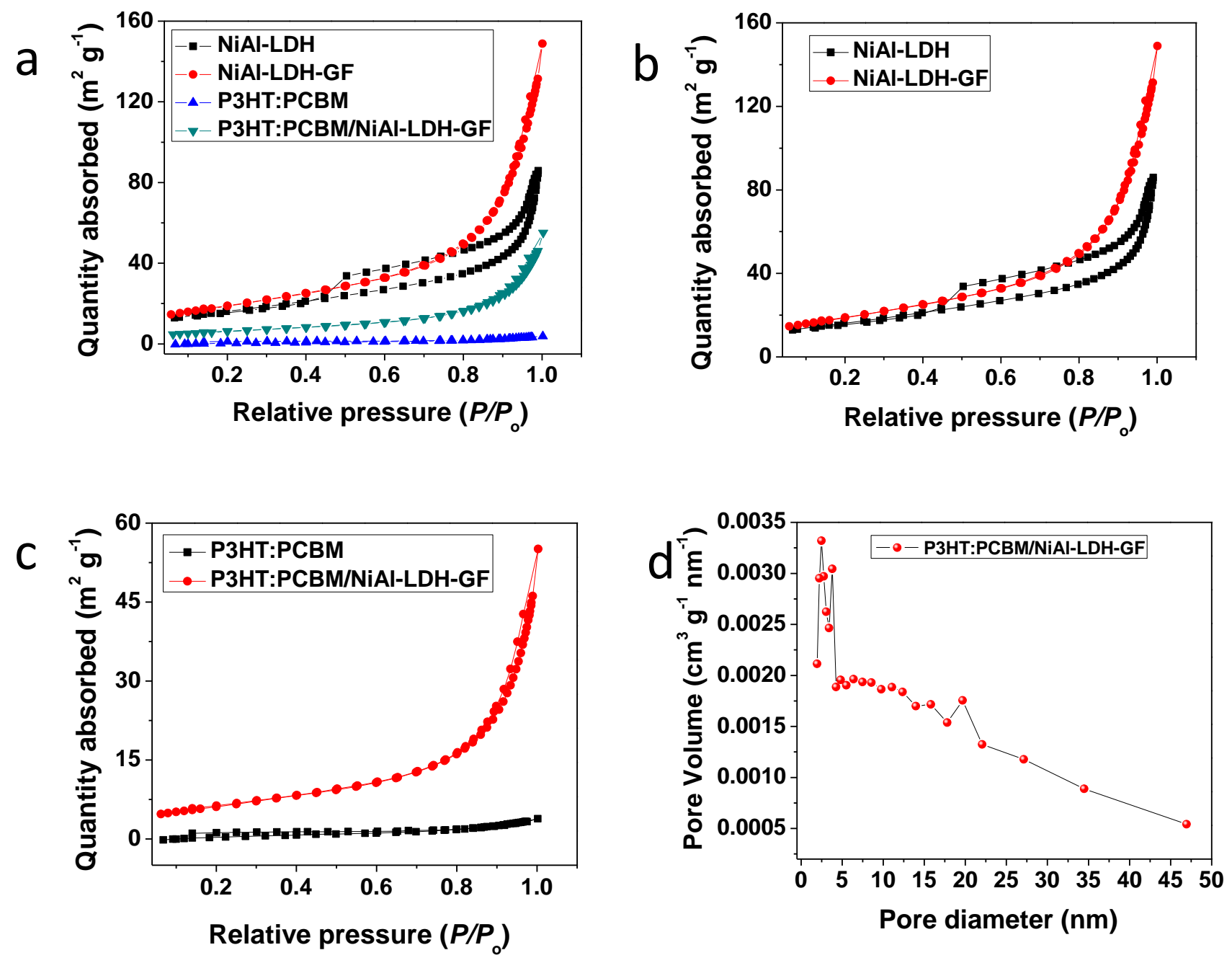

Fig. 4 
a

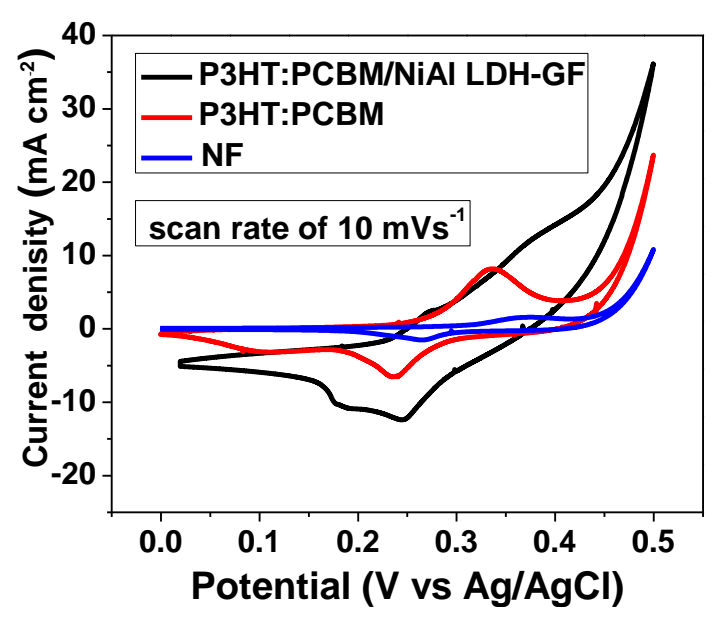

C

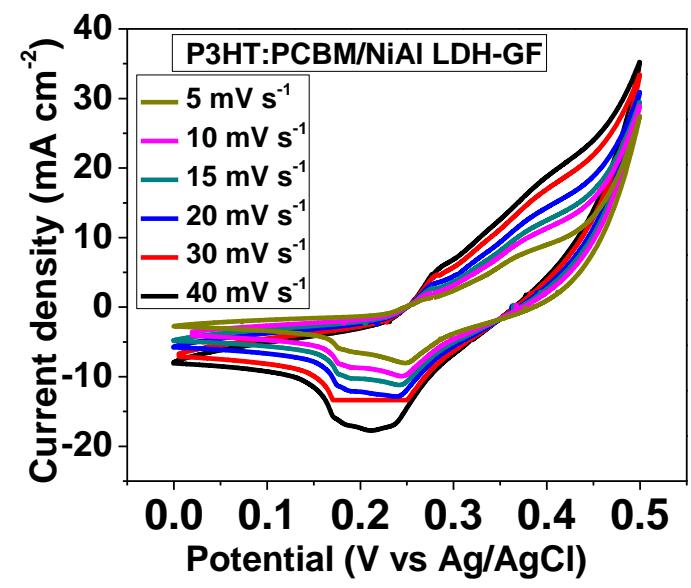

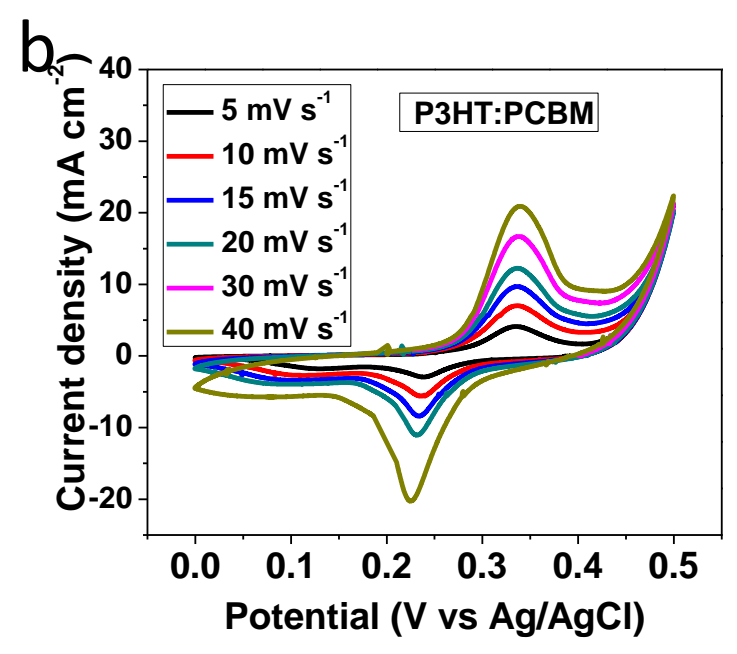

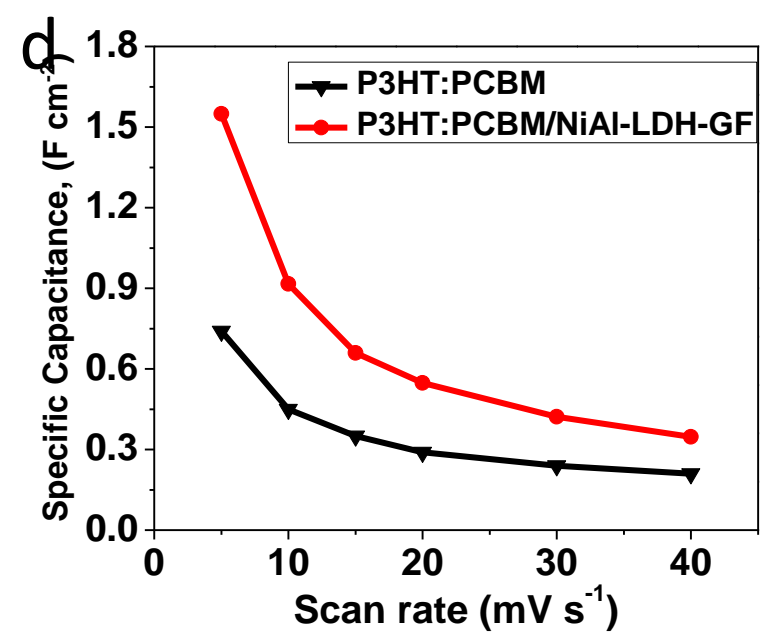

Fig. 5 

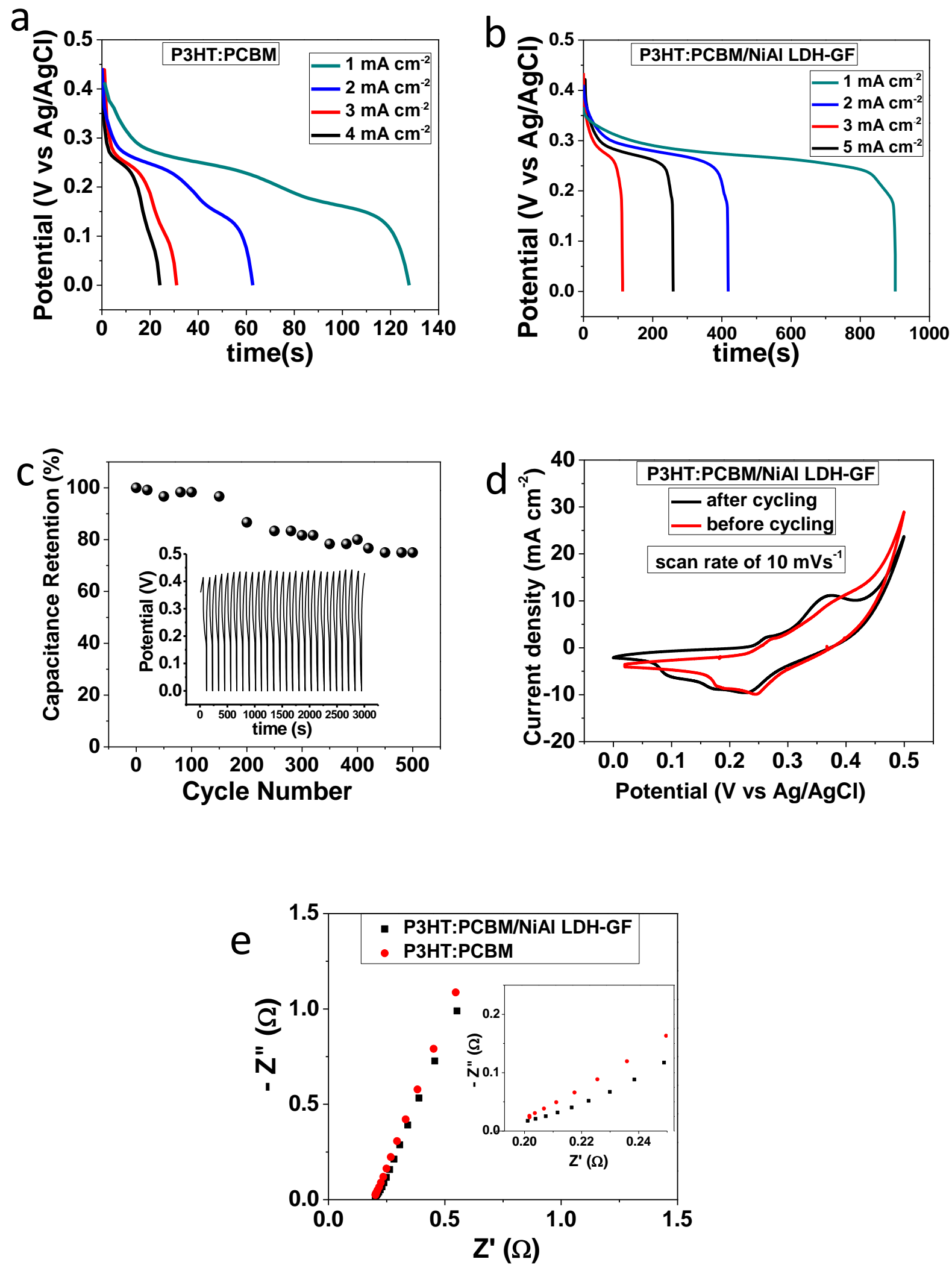

Fig. 6 